\title{
Amphetamine facilitation of win-shift radial-arm maze retention: The involvement of peripheral adrenergic and central dopaminergic systems
}

\author{
CEDRIC L. WILLIAMS, MARK G. PACKARD, and JAMES L. MCGAUGH \\ University of California, Irvine, California
}

\begin{abstract}
In these experiments we examined the role of peripheral and central catecholamine systems in mediating the memory-improving effects of $4-\mathrm{OH}$ amphetamine and $d$-amphetamine in an eightarm radial maze task. Sotalol (a peripherally acting $\beta$-adrenergic antagonist), propranolol (a peripherally and centrally acting $\beta$-adrenergic antagonist), or haloperidol (a dopaminergic antagonist) was administered prior to injection of amphetamine. Rats were first allowed to obtain food pellets placed in four of the eight maze arms and then were returned to their home cages. After a delay, food pellets were placed only in the four arms that were blocked prior to the delay, and each rat was returned to the maze and given access to all eight arms. Entries into the baited arms were scored as correct responses. On the experimental day, the animals received intraperitoneal injections of $0.9 \%$ saline, sotalol $(5.0 \mathrm{mg} / \mathrm{kg})$, propranolol $(2.0 \mathrm{mg} / \mathrm{kg})$, haloperidol $(0.5$ or $1.0 \mathrm{mg} / \mathrm{kg})$, or a combination of propranolol $(2.0 \mathrm{mg} / \mathrm{kg})$ and haloperidol $(0.5 \mathrm{mg} / \mathrm{kg}) 10 \mathrm{~min}$ before training, and subcutaneous injections of either saline, $d$-amphetamine $(1.0 \mathrm{mg} / \mathrm{kg})$, or $4-\mathrm{OH}$ amphetamine $(2.0 \mathrm{mg} / \mathrm{kg})$ immediately after they completed four alley entrances. Retention was tested $18 \mathrm{~h}$ later. Posttraining administration of 4-OH amphetamine or $d$-amphetamine produced a significant improvement in retention relative to saline controls $(p<.01)$. Sotalol and propranolol significantly blocked the improvement in retention produced by $4-\mathrm{OH}$ amphetamine $(p<.05)$, but not that produced by $d$-amphetamine. However, the effect of $d$-amphetamine on retention was completely blocked by $1.0 \mathrm{mg} / \mathrm{kg}$ of haloperidol $(p<.01)$. The combined administration of propranolol $(2.0 \mathrm{mg} / \mathrm{kg})$ and the lower dose of haloperidol $(0.5 \mathrm{mg} / \mathrm{kg})$ did not attenuate the retention-enhancing effects of $d$-amphetamine. These findings suggest that the memory-improving effects of posttraining amphetamine are mediated by influences involving peripheral adrenergic and central dopaminergic systems.
\end{abstract}

It is well established that $d$-amphetamine influences learning and memory in a number of different species, ranging from rodents to man (Gray, Pickering, Hemsley, Dawling, \& Gray, 1992; Kamien \& Woolverton, 1989; Martinez, Jensen, et al., 1980). In rats and mice, $d$ amphetamine produces dose-dependent enhancement of retention performance when given either before or shortly after acquisition (Krivanek \& McGaugh, 1969) and when administered either systemically (Martinez, Jensen, et al., 1980; Strupp, Bunsey, Levitsky, \& Kesler, 1991) or infused directly into specific brain regions (Packard \& White, 1991; White \& Viaud, 1991).

Previous findings suggest that the effects of $d$-amphetamine on memory are due, in part, to influences on peripheral catecholamine systems. It has been shown that $d$-amphetamine facilitates retention in inhibitory and ac-

This research was supported by NSF (BNS-9006175) and University of California Presidents Fellowship (C.L.W.); National Research Service Award (1 F32NS08973-01) from NINDS (M.G.P.); and USPHS Grant MH 12526 from NIDA and NIMH (J.L.M.). Address correspondence and reprint requests to $C$. L. Williams, Center for the Neurobiology of Learning and Memory, University of California, Irvine, CA 92717-3800. tive avoidance learning tasks when administered peripherally immediately after training (Martinez et al., 1983; Martinez, Jensen, et al., 1980). These effects, however, are attenuated by surgical removal of the adrenal medulla, a major source of peripheral catecholamines (Martinez, Vasquez, et al., 1980). The view that $d$-amphetamine modulates memory, at least in part by influencing peripheral catecholamines, is further supported by the finding that 4-OH amphetamine, a derivative of $d$-amphetamine with a limited capacity to enter the brain (Day, 1979), also facilitates retention in these learning tasks when given immediately after training (Martinez et al., 1983; Martinez, Jensen, et al., 1980). The facilitating effects of 4$\mathrm{OH}$ amphetamine and $d$-amphetamine on retention is not limited to learning conditions involving aversive stimulation. Posttraining peripheral administration of both forms of amphetamine also improves retention performance in appetitive tasks (Oscos, Martinez, \& McGaugh, 1988; Packard \& White, 1991; Packard, Williams, \& McGaugh, 1992; Strupp et al., 1991).

Other evidence suggests that systemically administered $d$-amphetamine may modulate memory by directly influencing the brain's neurotransmitter systems; $d$-amphetamine is a mixed catecholamine agonist that readily enters 
the brain when administered peripherally, and it augments the release of norepinephrine and dopamine (Weiner, 1980). Peripheral administration of $d$-amphetamine in doses that are known to improve memory also increases brain concentrations of dopamine (Ivens, Janak, \& Martinez, 1992) and norepinephrine (Kuczenski \& Segal, 1992).

In the present experiments we examined the involvement of peripheral adrenergic as well as central dopaminergic and noradrenergic systems in the memorymodulating effects of the amphetamines in a radial-arm maze task. Rats trained in the radial maze received a pretraining injection of either sotalol, the peripherally acting adrenergic receptor antagonist, propranolol, a central and peripherally acting noradrenergic antagonist, haloperidol, which blocks dopaminergic receptors in both the brain and periphery, or saline. Immediately following training, 4-OH amphetamine, $d$-amphetamine, or saline was administered peripherally. Retention was assessed $18 \mathrm{~h}$ after training.

\section{GENERAL METHOD}

\section{Subjects}

Ninety-five male Sprague-Dawley rats (Charles River Laboratories) with weights of $250-275 \mathrm{~g}$ were housed separately and maintained on a standard 12:12-h light:dark cycle (lights on at 7:00 a.m.). On arrival in the laboratory, food and water were available ad lib for 1 week. The animals' weights were then reduced to $85 \%$ of their ad-lib feeding weights over 5 to 7 days and were maintained at that level for the duration of the experiment.

\section{Apparatus}

Radial-arm maze training was conducted in an elevated $(60 \mathrm{~cm})$ wooden maze painted flat gray. The center platform of the maze (40 cm in diameter) was connected to eight $60 \times 9 \mathrm{~cm}$ arms extending radially. A recessed food well $(1 \times 2 \mathrm{~cm})$ was placed at the end of each arm. The maze was surrounded by various extramaze cues, including an animal cage rack, the seated experimenter, a table, a 15-W lamp, and a horizontally striped wall poster on the wall opposite to a vertically striped wall poster.

\section{Drugs}

The drugs that were used included $d$-amphetamine (Sigma), $d l$ 4-hydroxyamphetamine (4-OH amphetamine; Smith, Kline, \& French), sotalol (Bristol Myers), propranolol (Sigma), and haloperidol (Sigma). All of the antagonists were dissolved in 0.9\% physiological saline, with the exception of haloperidol (dissolved in one drop of acetic acid and $70 \%$ ethanol in $0.9 \%$ saline), and were administered in a volume of $1.0 \mathrm{ml} / \mathrm{kg}$. The receptor antagonists were administered intraperitoneally (i.p.) before training, and the amphetamines were administered subcutaneously (s.c.) on the dorsal surface of the neck immediately after training.

\section{Training Procedures}

The rats were habituated to the maze on 2 consecutive days. During the habituation sessions no food was available in the maze, and the animals were allowed to explore the eight maze arms for a period of $5 \mathrm{~min}$. Then they were returned to their home cages and given 10 Noyes Formula " A" food pellets (P. J. Noyes Co., Lancaster, NH). The food-rewarded training trials began on Day 3. On each day of food reward, four arms were randomly selected and baited with a single food pellet placed in the food wells located at the end of each arm. The remaining four arms were blocked by removable Plexiglas doors. The rats were first allowed to obtain the food pellets placed in each of the four open arms. They were then returned to their home cages. After a delay, each rat was returned to the maze and given a retention test with all eight arms open, but with food pellets placed only in the four arms that were blocked prior to the delay. Entries of arms not entered prior to the delay were scored as correct responses, whereas entries into unbaited arms were scored as errors.

The preliminary training was conducted in two phases. The delay between the initial trial and each retention test in the first phase was $5 \mathrm{~min}$. The delay in Phase 2 was extended to $15 \mathrm{~min}$. The rats were advanced from Phase 1 to Phase 2 when they made no more than five arm entries (i.e., only one error or visit to an unbaited arm) in locating the food pellets contained in the four new maze arms on the retention test on 2 consecutive days.

\section{Drug Experiments}

The drug experiments were initiated on the day after an animal reached the criterion at the $15-\mathrm{min}$ delay. On this day, $10 \mathrm{~min}$ before training, the animals received i.p. injections of either $0.9 \%$ saline, sotalol $(5.0 \mathrm{mg} / \mathrm{kg})$, propranolol $(2.0 \mathrm{mg} / \mathrm{kg})$, haloperidol $(0.5 \mathrm{mg} / \mathrm{kg})$, or the combination of propranolol $(2.0 \mathrm{mg} / \mathrm{kg})$ and haloperidol $(0.5 \mathrm{mg} / \mathrm{kg})$, mixed in the form of a cocktail. They were then placed into the maze and allowed to obtain food pellets located in the four open arms. Immediately after obtaining the pellets, the rats were removed from the maze and given an s.c. injection of saline, $d$-amphetamine $(1.0 \mathrm{mg} / \mathrm{kg})$, or $4-\mathrm{OH}$ amphetamine $(2.0 \mathrm{mg} / \mathrm{kg})$ and returned to their home cages. The animals were retained in the testing room until the retention test $18 \mathrm{~h}$ later. The retention test procedures were the same as those used for training: entries of maze arms not visited prior to the 18-h delay were recorded as correct responses.

A rank-order method was used to assign each animal to a respective treatment group when it reached the 15 -min criterion (i.e., first rat to reach criterion, saline; second rat, $d$-amphetamine; third rat, 4-OH amphetamine; fourth rat, 4-OH amphetamine, etc.). This method was used to ensure that the groups were comparable in the mean number of days to criterion.

\section{Statistical Analysis}

The number of correct responses made on the retention test are expressed as mean $(M \pm S E M)$ percent correct for each treatment group. Between-group comparisons were analyzed with a one-way analysis of variance (ANOVA), followed by Fisher's post hoc tests. Values of $p<.05$ were considered significant.

\section{EXPERIMENT 1}

The purpose of the first experiment was to determine whether the enhancement in radial maze retention produced by posttraining systemic administration of $4-\mathrm{OH}$ and $d$-amphetamine (Packard et al., 1992) is mediated by influences involving peripheral adrenergic catecholamines. If the amphetamines facilitate retention through a common mechanism involving activation of adrenergic catecholamine release in the periphery, then their modulatory effects should be attenuated by blocking peripheral adrenergic receptors with the receptor antagonist sotalol. Three groups received pretraining injections of saline, followed by posttraining injections of saline (Sal-Sal), $2.0 \mathrm{mg} / \mathrm{kg}$ of $4-\mathrm{OH}$ amphetamine (Sal-4OH), or $1.0 \mathrm{mg} / \mathrm{kg}$ of $d$-amphetamine (Sal-Amph). The animals in the other groups received injections of the peripherally acting $\beta$-adrenergic receptor antagonist sotalol $(5.0 \mathrm{mg} / \mathrm{kg})$ before training and injections of saline (Sotl-Sal), $2.0 \mathrm{mg}$ / 


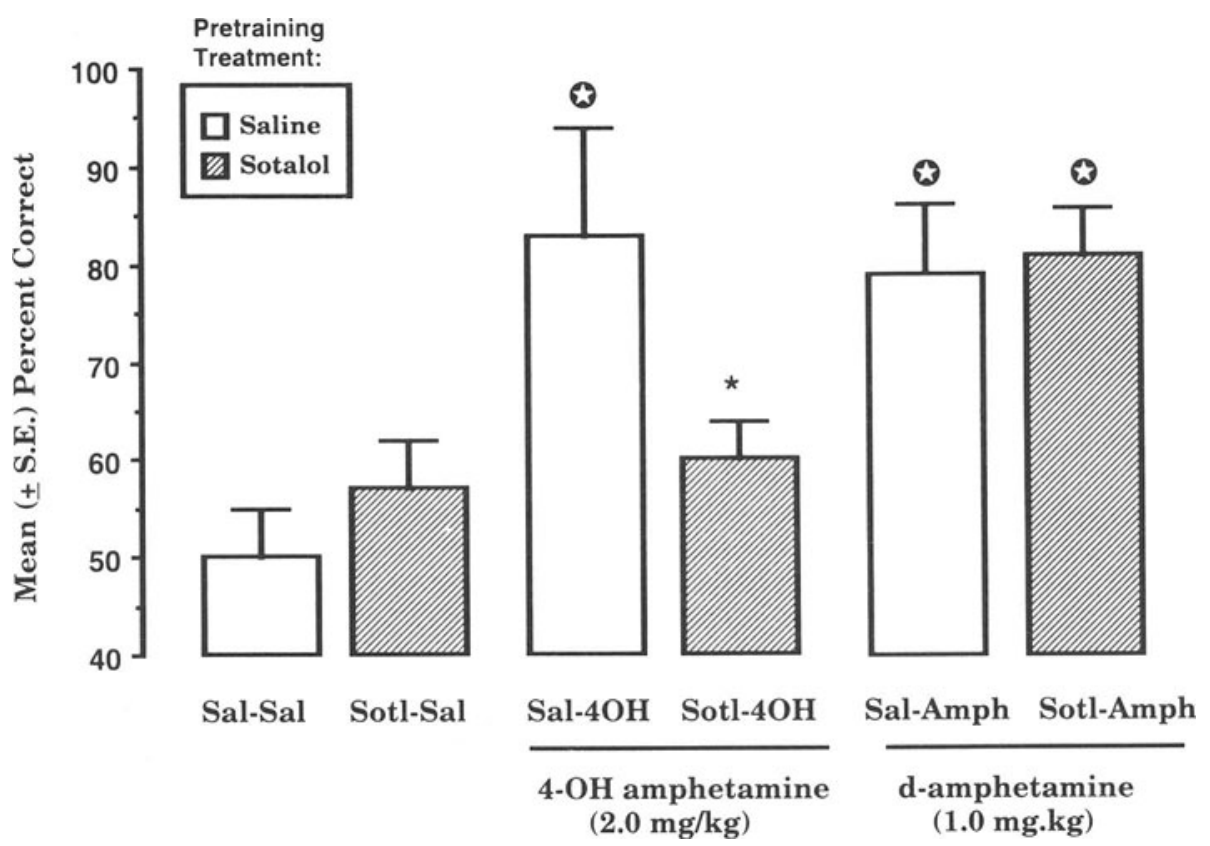

Figure 1. Effects of peripheral adrenergic blockade with sotalol $(5.0 \mathrm{mg} / \mathrm{kg})$ on $4-\mathrm{OH}$-amphetamine$(2.0 \mathrm{mg} / \mathrm{kg})$ or $d$-amphetamine-induced $(1.0 \mathrm{mg} / \mathrm{kg})$ improvement in win-shift retention. Bars represent mean $( \pm S E)$ percent correct on the retention test. Open stars indicate significantly different from SalSal or Sotl-Sal $(p<.01$ and $p<.05$, respectively). Asterisk indicates different from Sal $4-0 \mathrm{H}(p<.05)$.

$\mathrm{kg}$ of $4-\mathrm{OH}$ amphetamine (Sotl-4OH), or $1.0 \mathrm{mg} / \mathrm{kg}$ of $d$-amphetamine (Sotl-Amph) immediately after training. Retention was assessed $18 \mathrm{~h}$ later.

\section{Results}

The effects of sotalol on 4-OH-amphetamine- or $d$ amphetamine-induced improvement in win-shift retention performance is shown in Figure 1. A one-way ANOVA of the percentage of correct choices on the retention test indicated a significant group effect $[F(5,28)=4.76, p<$ .002]. Between-group comparisons made with Fisher's post hoc tests confirmed our previous findings (Packard et al., 1992) that either $d$-amphetamine $(1.0 \mathrm{mg} / \mathrm{kg})$ or 4-OH amphetamine $(2.0 \mathrm{mg} / \mathrm{kg})$ produces a significant improvement in radial maze retention performance relative to saline-treated controls $(p<.01)$, respectively. In comparison with the Sotl-Sal group, the groups given Sal$4 \mathrm{OH}$ or Sal-Amph also made a significantly greater percentage of correct choices $(p<.01$ and $p<.05$, respectively) on the retention test.

Sotalol significantly attenuated the improvement in retention produced by posttraining administration of 4$\mathrm{OH}$ amphetamine. The Sotl-4OH group made significantly fewer correct responses on the retention test than did the Sal-4OH group $(p<.05)$. Furthermore, the retention performance of the Sotl-4OH group did not differ from that of the Sal-Sal controls ( $p=.15, \mathrm{n} . \mathrm{s}$.). In contrast, sotalol did not attenuate the facilitating effect of $d$ amphetamine on retention. The Sal-Amph and Sotl-Amph groups did not differ in the percentage of correct responses $(p=.76$, n.s.). Furthermore, the Sotl-Amph group performed significantly better than the group given Sotl-Sal $(p<.05)$ or Sal-Sal $(p<.01)$.

\section{EXPERIMENT 2}

The findings of Experiment 1, indicating that the retention-enhancing effects of 4-OH amphetamine are blocked by sotalol, are consistent with other evidence (Martinez, Jensen, et al., 1980) suggesting that the effects of 4-OH amphetamine on memory are mediated by peripheral adrenergic systems. The finding that sotalol did not block the influences of $d$-amphetamine on retention suggests that the $d$-amphetamine effects do not require activation of peripheral adrenergic receptors. Experiment 2 was undertaken to determine whether the retentionenhancing effects of $d$-amphetamine are altered by antagonizing noradrenergic receptors in both the periphery and the brain. The $\beta$-adrenergic receptor antagonist propranolol was used for this experiment because it is known to enter the brain readily when administered systemically. The dose of propranolol used in this experiment was chosen on the basis of dosages that have been shown to attenuate the effects of treatments affecting noradrenergic systems in other published reports. For example, doses of propranolol ranging from 0.5 to $2.0 \mathrm{mg} / \mathrm{kg}$ were sufficient to attenuate the effects on retention produced by systemically administered epinephrine 
(Gold \& van Buskirk, 1978; Introini-Collison, Saghafi, Novack, \& McGaugh, 1992), beta-endorphin (Netto, Oliveira, Gianlupi, \& Quillfeldt, 1990), naloxone (Introini-Collison \& Baratti, 1986), dipivefrin (IntroiniCollison et al., 1992), clenbuterol, or salbutamol (McElroy, Stimmel, \& O'Donnell, 1989). Systemic administration of propranolol in this dose range also blocks the effects on memory that are produced by electrical stimulation of the amygdala (Sternberg \& Gold, 1981) or the frontal cortex (Sternberg \& Gold, 1980) and also attenuates the transient decrease in brain and adrenal medulla catecholamine concentrations produced by peripherally administered epinephrine (Gold \& van Buskirk, 1978).

On the basis of these findings, we gave the animals in Experiment 2 pretraining injections of propranolol $(2.0 \mathrm{mg} / \mathrm{kg}$ ) and posttraining injections of saline (PropSal), $2.0 \mathrm{mg} / \mathrm{kg}$ of $4-\mathrm{OH}$ amphetamine (Prop-4OH), or $1.0 \mathrm{mg} / \mathrm{kg}$ of $d$-amphetamine (Prop-Amph). The effects of propranolol on amphetamine-induced enhancement of retention was assessed by comparing the performance of these groups with the groups given pretraining injections of saline in Experiment 1 (i.e., Sal-Sal, Sal-4OH, and SalAmph). If $d$-amphetamine influences radial maze retention by actions involving brain norepinephrine systems, then the effects should be attenuated by blocking central noradrenergic receptors with propranolol.

\section{Results}

The effects of propranolol on 4-OH-amphetamine- or $d$-amphetamine-induced improvement in retention perfor- mance is shown in Figure 2. Propranolol blocked the effect of 4-OH amphetamine on retention. The animals in the Prop-4OH group made significantly fewer correct responses on the retention test than did those in the $\mathrm{Sal}-4 \mathrm{OH}$ group $(p<.01)$. The retention performance of the Prop$40 H$ group did not differ from that of the Sal-Sal group or the Prop-Sal group. The retention performance of the Prop-Amph group was significantly better than that of the Sal-Sal and Prop-Sal groups $(p<.05$ for both comparisons) and did not differ from that of the Sal-Amph group.

\section{EXPERIMENT 3}

The findings of Experiment 2 indicate that propranolol, like sotalol (Experiment 1), blocked the retentionenhancing effects of 4-OH amphetamine. However, propranolol did not significantly attenuate the effects of $d$-amphetamine. To further examine the basis of $d$ amphetamine facilitation of retention, in Experiment 3 we examined the possible involvement of dopamine. The nonspecific dopamine receptor antagonist haloperidol $(0.5 \mathrm{mg} / \mathrm{kg})$ was administered i.p. $10 \mathrm{~min}$ before radial maze training, and saline [Hal (0.5)-Sal] or $1.0 \mathrm{mg} / \mathrm{kg}$ of $d$-amphetamine [Hal (0.5)-Amph] was given s.c. immediately after the four choices. Two additional groups of rats received posttraining i.p. injections of a higher dose of haloperidol $(1.0 \mathrm{mg} / \mathrm{kg})$ or saline, followed immediately by an s.c. injection of $d$-amphetamine [Hal (1.0)Amph] or saline [Hal (1.0)-Sal]. It was necessary to administer the higher dose of haloperidol posttraining, be-

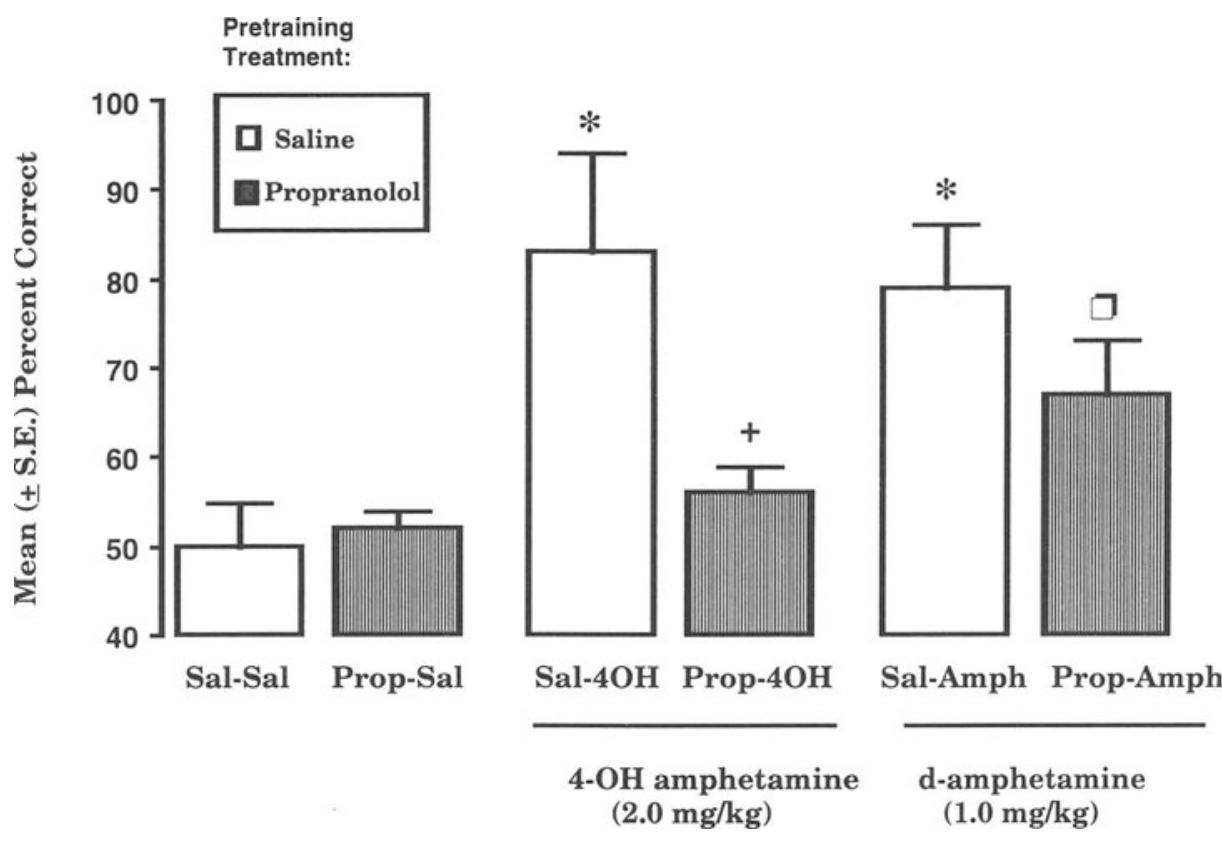

Figure 2. Effects of central and peripheral noradrenergic blockade with propranolol $(2.0 \mathrm{mg} / \mathrm{kg})$ on 4 OH-amphetamine- $(2.0 \mathrm{mg} / \mathrm{kg})$ or d-amphetamine-induced $(1.0 \mathrm{mg} / \mathrm{kg})$ facilitation of retention performance. Asterisks indicate significantly different from Sal-Sal or Prop-Sal $(p<.01)$. Bars represent mean $( \pm S E)$ percent correct on the retention test. Cross indicates different from Sal-4-OH $(p<.01)$. Open box indicates different from Sal-Sal and Prop-Sal $(p<.05)$. 

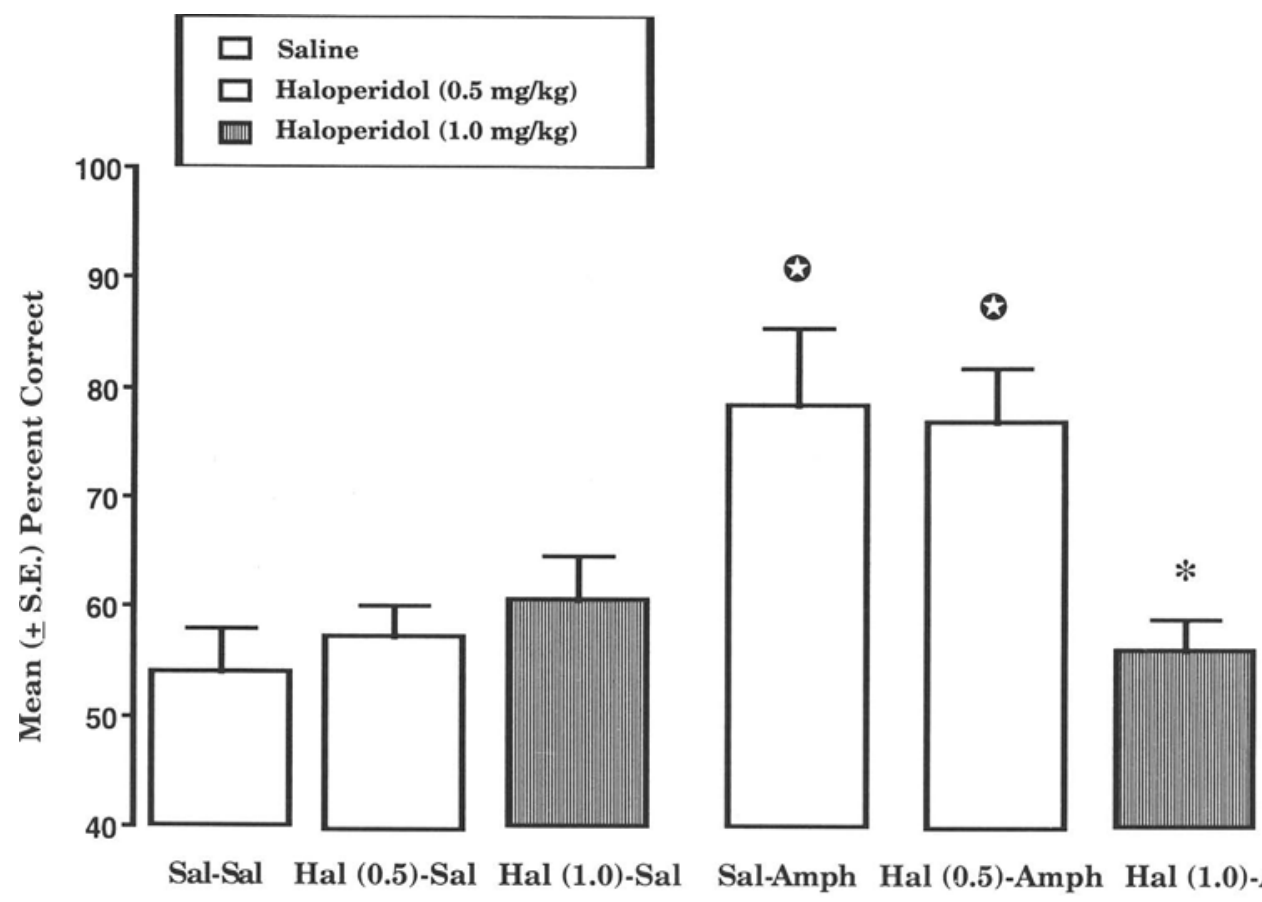

Sal-Amph Hal (0.5)-Amph Hal (1.0)-Amph

$$
\begin{gathered}
\text { d-amphetamine } \\
(1.0 \mathrm{mg} / \mathrm{kg})
\end{gathered}
$$

Figure 3. The effects of pre- or posttraining administration of haloperidol $(0.5 \mathrm{mg} / \mathrm{kg}$ and $1.0 \mathrm{mg} / \mathrm{kg}$, respectively) on the enhancement in win-shift retention by posttraining $d$-amphetamine. Bars represent mean ( $\pm S E$ ) percent correct on the retention test. Open stars indicate significantly different from Sal-Sal, Hal (0.5)-Sal, or Hal (1.0)-Sal $(p<.01)$. Asterisk indicates different from Sal-Amph or Hal $(0.5)$-Amph $(p<.01)$.

cause this dose inhibited locomotion and influenced the animals' capacity to enter the four open arms when given pretraining. As in the previous experiments, retention was assessed $18 \mathrm{~h}$ later.

\section{Results}

The effects of haloperidol on the enhancement in retention produced by $d$-amphetamine are shown in Figure 3 . A one-way ANOVA of the percentage of correct choices on the retention test indicated a significant overall effect $[F(5,35)=5.11, p<.001]$. The effect of $d$-amphetamine on retention was not altered by the lower dose of haloperidol $(0.5 \mathrm{mg} / \mathrm{kg})$. The Hal $(0.5)$-Amph group performed as well as the Sal-Amph group: The Hal (0.5)Amph group made a significantly greater percentage of correct choices on the retention test than did the control animals given Sal-Sal, Hal (0.5)-Sal, or Hal (1.0)-Sal $(p<.01)$. The effects of $d$-amphetamine were, however, attenuated by posttraining administration of the higher dose of haloperidol $(1.0 \mathrm{mg} / \mathrm{kg})$. The Hal (1.0)-Amph group made a significantly lower percentage of correct responses on the retention test than did the Sal-Amph group $(p<.01)$ or the group given the lower dose of haloperidol and amphetamine [Hal (0.5)-Amph] $(p<$ $.01)$.

\section{EXPERIMENT 4}

In Experiments 2 and 3 we examined the separate contributions of dopaminergic and noradrenergic systems in mediating the effects of $d$-amphetamine on radial maze retention performance. Because $d$-amphetamine is a mixed catecholamine agonist and could modulate memory storage by simultaneously influencing both neurotransmitter systems, a final experiment was conducted to determine whether the effects of $d$-amphetamine on retention would be attenuated by the combined administration of propranolol and haloperidol in doses that, when administered alone, were ineffective. This possibility was also suggested by the findings in Experiment 2. The retention performance of the animals given amphetamine plus propranolol was slightly, but not significantly, poorer than that of the animals given amphetamine plus saline. The animals in Experiment 4 received pretraining i.p. injec- 


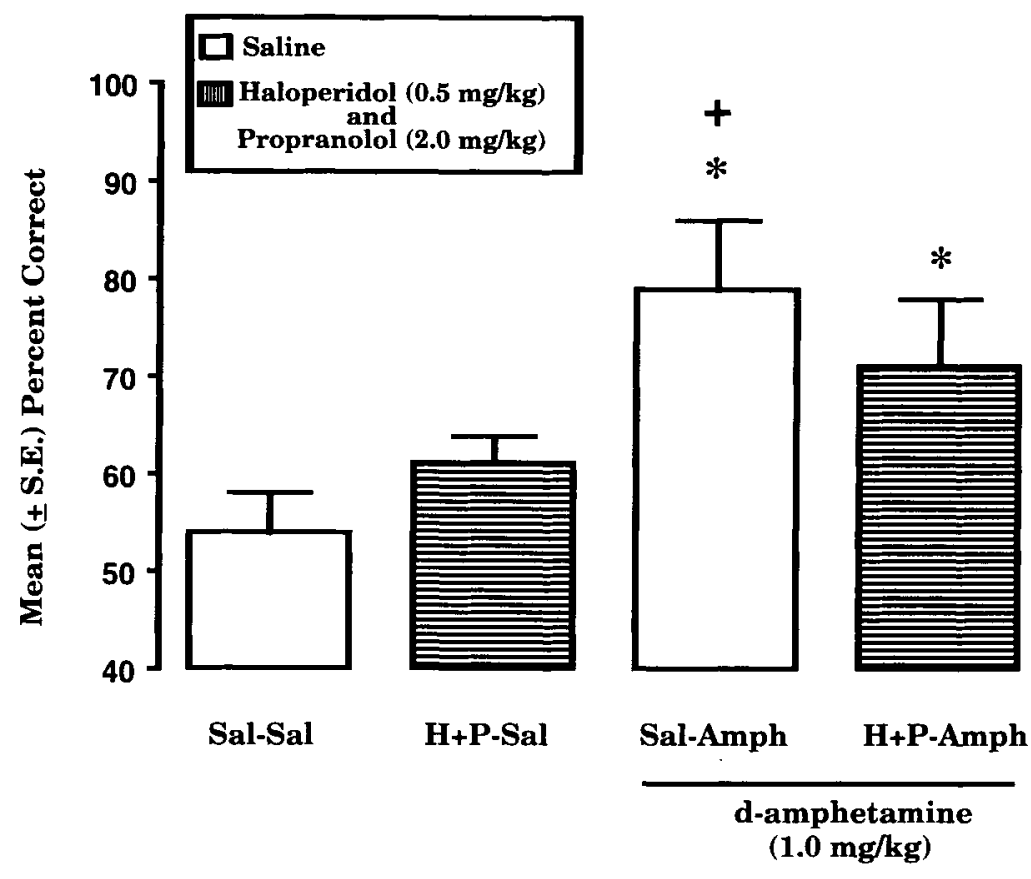

Figure 4. The effects of combined noradrenergic and dopaminergic blockade with propranolol $(2.0 \mathrm{mg} / \mathrm{kg})$ and haloperidol $(0.5 \mathrm{mg} / \mathrm{kg})$ on amphetamine-induced facilitation of radial maze retention performance. Bars represent mean $( \pm S E)$ percent correct on the retention test. Cross indicates significantly different from Sal-Sal ( $p<.01$ ). Asterisks indicate different from either Sal-Sal or H+P-Sal $(p<.05)$.

tions of either saline or a combination of propranolol $(2.0 \mathrm{mg} / \mathrm{kg})$ and haloperidol $(0.5 \mathrm{mg} / \mathrm{kg})$, and posttraining injections of either saline $(\mathrm{H}+\mathrm{P}-\mathrm{Sal})$ or $d$ amphetamine (H+P-Amph).

\section{Results}

The influence of propranolol plus the lower dose of haloperidol on the retention-facilitating effects of $d$ amphetamine is shown in Figure 4. A one-way ANOVA of the percentage of correct choices on the retention test indicated a significant group effect $[F(3,27)=4.17, p<$ .01]. Between-group comparisons made with Fisher's post hoc tests revealed that the combined treatments did not attenuate the effects of $d$-amphetamine on retention performance. The retention performance of the $\mathrm{H}+\mathrm{P}$ Amph group was significantly better than that of the SalSal group $(p<.05)$ as well as the H $+\mathrm{P}-$ Sal group $(p<$ $.05)$.

\section{DISCUSSION}

In the present experiments we examined the contribution of peripheral adrenergic as well as central dopaminergic and noradrenergic functions to the memory-enhancing properties of $d$-amphetamine and 4-OH amphetamine. The findings of Experiment 1 replicate our previous results, which indicated that radial maze retention performance is enhanced by posttraining systemic administration of either $d$-amphetamine (which readily enters the brain) or 4-OH amphetamine (Packard et al., 1992), a peripherally acting amphetamine analog that passes the blood-brain barrier poorly. Pretraining blockade of peripheral and/or central adrenergic receptors attenuated the memoryenhancing effect of systemically administered 4-OH amphetamine, but not that of $d$-amphetamine. The effects of 4-OH amphetamine were blocked by sotalol, an adrenergic receptor blocker that does not readily enter the brain when administered systemically, as well as by propranolol, the $\beta$-adrenergic antagonist that freely passes the blood-brain barrier. It seemed that the attenuation of 4-OH-amphetamine-induced memory facilitation was not due to any effects that the antagonists might have had on acquisition, because the retention performance of the groups given pretraining injections of only sotalol or propranolol did not differ from that of the control groups. Furthermore, the administration of these drugs alone have not been shown to influence retention when given prior to training in the radial-arm maze task (Beatty \& Rush, 1983).

The findings of Experiment 1 are consistent with previous evidence suggesting that 4-OH amphetamine influences radial maze retention through effects mediated by peripheral adrenergic receptors (Packard et al., 1992). They are also consistent with the view that 4-OH modulates memory, at least in part, by activating the release of epinephrine from the adrenal medulla, because the ef- 
fects of epinephrine are also attenuated by sotalol and propranolol (Introini-Collison et al., 1992). Although the processes mediating the effects of 4-OH on memory subsequent to activation of peripheral adrenergic receptors have not been determined, there is evidence suggesting that the effect may involve norepinephrine release in the brain. Previous findings have indicated that 4-OH stimulates the release of epinephrine from the adrenal medulla (Wellman \& Watkins-Freeman, 1984), and that elevations in peripheral concentrations of epinephrine in turn increase the release and turnover of norepinephrine in the brain (Gold \& van Buskirk, 1978). Thus, the memorymodulating effects of both 4-OH and epinephrine are sensitive to treatments that modify the activity of central and peripheral adrenoceptors.

The finding that sotalol did not attenuate the effects of $d$-amphetamine on retention suggests that the influences of $d$-amphetamine on win-shift retention are not mediated exclusively through actions on peripheral adrenergic receptors. These results appear to be at variance with findings suggesting that the effects of $d$-amphetamine on retention in aversive learning tasks involve peripheral adrenergic mechanisms. For example, surgical removal of the adrenal medulla, one source of peripheral epinephrine, or destruction of peripheral presynaptic catecholamine nerve terminals with the neurotoxin 6-OHDA attenuates the facilitating effects of $d$-amphetamine on inhibitory avoidance retention (Martinez, Jensen, et al., 1980; Martinez, Vasquez, et al., 1980).

The finding that the effects of $d$-amphetamine on retention were not blocked by propranolol contrasts with evidence suggesting that norepinephrine is involved in mediating some of the pharmacological and electrophysiological effects of $d$-amphetamine. For example, systemic administration of $d$-amphetamine increases norepinephrine concentrations in both the periphery (Vogel et al., 1984) and the brain (Kuczenski \& Segal, 1992; Martinez et al., 1983). Furthermore, the effects of $d$ amphetamine on electrical activity in the brain are partially blocked by propranolol (Jahromi et al., 1991) and are completely suppressed by lesions of central noradrenergic pathways with 6-OHDA (Curet et al., 1992).

The enhancement produced by $d$-amphetamine in win-shift retention was also not blocked by pretraining administration of a low dose of the dopamine receptor blocker haloperidol when it was given either alone or in combination with propranolol. However, the retentionenhancing effects of $d$-amphetamine were completely blocked by posttraining administration of a higher dose of haloperidol. Although $d$-amphetamine influences both dopaminergic and noradrenergic activity when administered either systemically or intracerebrally (Kuczenski \& Segal, 1992; Perlow, Chiueh, Lake, \& Wyatt, 1980; Philips, Robson, \& Boulton, 1982), the present findings suggest that the effects of $d$-amphetamine on retention in the win-shift task are primarily mediated by influences on dopaminergic systems. The results of Experiments 3 and 4 are consistent with those from experiments with other behavioral learning tasks. Administration of $d$ amphetamine, either systemically or directly into the caudate nucleus, facilitates retention in a CER task (Viaud \& White, 1989; White, 1988). This effect is presumed to be mediated by actions on central dopamine systems, because the facilitation is attenuated by 6-OHDA lesions of dopaminergic nigrostriatal neurons (White, 1988). The present findings are also consistent with evidence that the effects of $d$-amphetamine on other behaviors involve activation of dopamine. For instance, the effects of $d$ amphetamine on rage and hyperreactivity in mice were suppressed by pretraining treatment with haloperidol and were not affected by propranolol (Xu, Shen, \& Zhang, 1992). In cats, $d$-amphetamine induces a significant dosedependent increase in arousal, which is reduced by pretreatment with haloperidol, but not propranolol (Lin et al., 1992). The increased pecking in chicks that is induced by $d$-amphetamine is decreased by pretreatment with $\mathrm{D} 1$ or D2 dopamine receptor antagonists, but is not influenced by administration of the noradrenergic receptor blocker propranolol (Zarrindast \& Namdari, 1992).

In sum, the evidence from the present experiments demonstrates that win-shift retention performance can be influenced by activation of peripheral or central neurochemical systems. The mechanisms that are responsible for mediating the memory-improving effects of 4-OH amphetamine on win-shift retention involve activation of peripheral $\beta$-adrenergic receptors. Although systemically administered $d$-amphetamine also influences peripheral adrenergic systems, the evidence obtained from these experiments indicates that $d$-amphetamine facilitates winshift retention performance primarily through influences on the brain's dopaminergic systems.

\section{REFERENCES}

Beatty, W. W., \& RuSh, J. R. (1983). Spatial working memory in rats: Effects of monoaminergic antagonists. Pharmacology, Biochemistry \& Behavior, 18, 7-12.

Curet, O., DeMontigny, C., Blier, P. (1992). Effect of desipramine and amphetamine on noradrenergic neurotransmission: Electrophysiological studies in the rat brain. European Journal of Pharmacology, 221, 59-70.

DAY, M. D. (1979). Autonomic pharmacology: Experimental and clinical aspects. New York: Churchill Livingstone.

Gold, P. E., \& VAN Buskirk, R. B. (1978). Posttraining brain norepinephrine concentrations: Correlation with retention performance of avoidance training with peripheral epinephrine modulation of memory processing. Behavioral Biology, 23, 509-520.

Gray, N. S., Pickering, A. D., Hemsley, D. R., Dawling, S., \& GraY, J. A. (1992). Abolition of latent inhibition by a single $5 \mathrm{mg}$ dose of $d$-amphetamine in man. Psychopharmacology, 107, 425-430.

IntroInI-Collison, I. B., \& BARATt, C. M. (1986). Opioid peptidergic systems modulate the activity of $\beta$-adrenergic mechanisms during memory consolidation processes. Behavioral \& Neural Biology, 46, 227-241.

Introini-Collison, I. B., Saghafi, D., Novack, G., \& McGaugh, J. L. (1992). Memory-enhancing effects of posttraining dipivefrin and epinephrine: Involvement of peripheral and central adrenergic receptors. Brain Research, 572, 81-86. 
Ivens, I. A., JANAK, P. H., \& MARTinez, J. L. (1992). Microdialysis measurement of striatal dopamine levels in freely moving rats after cocaine or amphetamine treatment. Proceedings of the Western Pharmacology Society, 35, 165-169.

Jahromi, S. S., Niesen, C., \& Carlen, P. L. (1991). Amphetamine actions on pre- and postpubertal rat hippocampal dentate granule neurons. Brain Research, 556, 33-43.

Kamien, J. B., \& Woolverton, W. L. (1989). A pharmacological analysis of the discriminative stimulus properties of $d$-amphetamine in thesus monkeys. Journal of Pharmacology \& Experimental Therapeutics, 248, 938-946.

KrIVANEK, J., \& MCGAUGH, J. L. (1969). Facilitating effects of preand post-training amphetamine administration on discrimination learning in mice. Agents \& Actions, 1, 36-42.

KuCZENSKI, R., \& SEgAL, D. S. (1992). Regional norepinephrine response to amphetamine using dialysis: Comparison with caudate dopamine. Synapse, 11, 164-169.

lin, J. S., Roussel, B., Akaoka, H., Fort, P., Debilly, G., \& Jouvet, M. (1992). Role of catecholamines in the modafinil and amphetamine induced wakefulness: A comparative pharmacological study in the cat. Brain Research, 591, 319-326.

Martinez, J. L., Ishikawa, K., Liang, K. C., Jensen, R. A., Bennett, C., Sternberg, D. B., \& McGaugh, J. L. (1983). 4-OH amphetamine enhances retention of an active avoidance response in rats and decreases regional brain concentrations of norepinephrine and dopamine. Behavioral Neuroscience, 97, 962-969.

Martinez, J. L., Jensen, R. A., Messing, R. B., Vasquez, B. J., Soumireu-Mourat, B., Geddes, D., Liang, K. C., \& McGaugh, J. L. (1980). Central and peripheral actions of amphetamine on memory storage. Brain Research, 182, 157-166.

Martinez, J. L., Vasquez, R. B., Rigter, H., Messing, R. B., Jensen, R. A., Liang, K. C., \& McGaugh, J. L. (1980). Attenuation of amphetamine-induced enhancement of learning by adrenal demedullation. Brain Research, 195, 433-443.

McElroy, J. F., Stimmel, J. J., \& O’Donnell, J. M. (1989). Effects of centrally acting $\beta$-adrenergic agonists on discrete trial conditioned avoidance behavior in rats. Psychopharmacology, 97, 108-114.

Netto, C. A., Oliveira, C. B., Gianlupi, A., \& Quillfeldt, J. (1990). Effect of atropine and propranolol on retrieval enhancement by a novel experience or by injection of beta-endorphin prior to testing in rats. Brazilian Journal of Medical \& Biological Research, 23, 59-63.

Oscos, A., Martinez, J. L., \& McGaugh, J. L. (1988). Effects of posttraining $d$-amphetamine on acquisition of an appetitive autoshaped lever press response in rats. Psychopharmacology, 95, 132-134.

PACKARD, M. G., \& WhITE, N. M. (1991). Dissociation of hippocampus and caudate nucleus memory systems by post-training intracerebral injection of dopamine agonists. Behavioral Neuroscience, 105, 295-306.

Packard, M. G., Williams, C. L., \& McGaugh, J. L. (1992). Enhancement of win-shift radial maze retention by peripheral posttrain- ing administration of $d$-amphetamine and 4-OH amphetamine. Psychobiology, 20, 280-285.

Perlow, M. J., Chiueh, C. C., Lake, C. R., \& Wratt, R. J. (1980) Increased dopamine and norepinephrine concentrations in primate CSF following amphetamine and phenylethylamine administration. Brain Research, 186, 469-473.

Philips, S. R., Robson, A. M., Boulton, A. A. (1982). Unstimulated and amphetamine-stimulated release of endogenous noradrenaline and dopamine from rat brain in vivo. Journal of Neurochemistry, 38, 1106-1110.

STERNBERG, D. B., \&oLD, P. E. (1980). Effects of $\alpha$-and $\beta$-adrenergic receptor antagonists on retrograde amnesia produced by frontal cortex stimulation. Behavioral \& Neural Biology, 29, 289-302.

STERnBERG, D. B., \& Gold, P. E. (1981). Retrograde amnesia produced by electrical stimulation of the amygdala: Attenuation with adrenergic antagonists. Brain Research, 211, 59-65.

Strupp, B. J., Bunsey, M., Levitsky, D., \& Kesler, M. (1991). Timedependent effects of post-trial amphetamine treatment in rats: Evidence for enhanced storage of representational memory. Behavioral \& Neural Biology, 56, 62-76.

VIAUD, M. D., \& WhITE, N. M. (1989). Dissociation of visual and olfactory conditioning in the neostriatum of rats. Behavioural Brain Research, 32, 31-42.

Vogel, W. H., Miller, J., DeTurck, K. H., \&outzahn, B. K. (1984). Effects of psychaactive drugs on plasma catecholamines during stress in rats. Neuropharmacology, 23, 1105-1108.

WEINER, N. (1980). Norepinephrine, epinephrine, and the sympathomimetic amines. In A. Goodman-Gilman, L. S. Goodman, \& A. Gilman (Eds.), The pharmacological basis of therapeutics (pp. 138-176). New York: MacMillan.

Wellman, P. J., \& Watkins-Freeman, P. A. (1984). Effects of 4hydroxyamphetamine on in vivo brown adipose tissue thermogenesis and feeding behavior in the rat. Behavioral Neuroscience, 98, 1060-1064.

WHITE, N. M. (1988). Effect of nigrostriatal dopamine depletion on the post-training, memory-improving effect of amphetamine. Life Sciences, 43, 7-12.

WhITE, N. M., \& VIAUD, M. (1991). Localized intracaudate dopamine D2 receptor activation during the post-training period improves memory for visual or olfactory conditioned emotional responses in rats. Behavioral \& Neural Biology, 55, 255-269.

Xu, J. H., Shen, H., \& ZHANG, Y. P. (1992). Amphetamine-induced rage reaction in mice and its mechanism. Yao Hsueh Hsueh Pao Acta Pharmaceutica Sinica, 27, 566-571.

ZARRINDAST, M.-R., \& NAMDARI, S. (1992). Ephedrine and amphetamineinduced pecking in chickens: Possible indirect D-1/D-2 dopaminergic mechanism. European Neuropsychopharmacology, 2, 135-140.

(Manuscript received August 27, 1993; revision accepted for publication November 22, 1993.) 